\title{
3D LIDAR Rapid Prototype Relief Model of the Jurassic Coast
}

\author{
Jeremy Gardiner \\ Ravensbourne \\ North Greenwich, London, UK \\ j.gardiner@rave.ac.uk
}

\section{INTRODUCTION}

For the bi-centenary of the birth of William Smith a section of the map he designed has been recreated using satellite data and will form part of the EVA exhibition 2016.

The traditional method for creating 3D landscape models is manually assembled plaster models. For the Jurassic Coast model I have employed a CNC computer numerically controlled milling machine. CNC (Computer Numerically Controlled) routing is a way of machining an object directly from (Computer Aided Design) data with a sharp, fast moving tool bit. I am working with geospatial data of the Jurassic coast supplied by Dr Andy Ford, Lecturer in Geoinformatics, School of Conservation Sciences of Bournemouth University, and this data was translated into "stl" files to create complex geometries for milling.

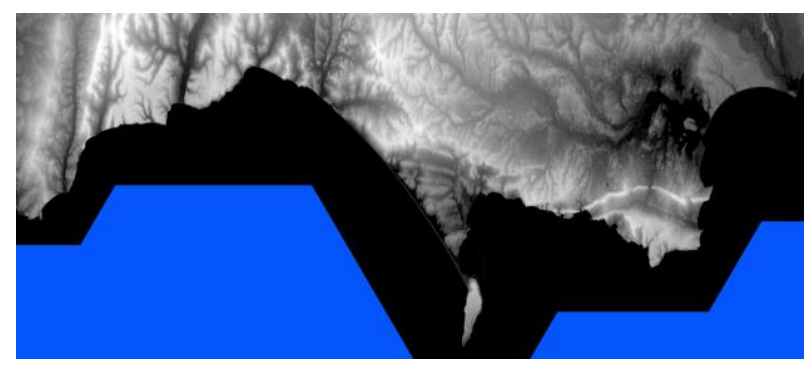

Figure 1: Satellite data of UNESCO world heritage site.

\section{MILLING THE MAP}

By starting with a solid block and removing unwanted material, the subtractive Rapid Prototyping (SRP) solution offered several advantages over 3D printers and other rapid prototyping systems which are more expensive, fragile and time consuming. For the Jurassic Coast model I have worked with Jake Durrant of Ravensbourne using a three axis machine, the Roland MDX 20 CNC 3 Axis mill benchtop milling machine. This delivered a smooth surface finish without post finishing and gave us tight tolerances up to $+/-0.001 \mathrm{~mm}$. Having three axis meant the cutter could be moved in the $x, y$ and $z$ axis simultaneously, whilst remaining perpendicular to the bed of the machine.

A CNC control computer reads and interprets a "toolpath" file, specially prepared for producing each specific part and sends a series of commands, called G-code, to the servo motors. Fast, precise carving turns flat sheet or block of material into complex part with recesses and holes of various depths, shapes and configurations. Each block has taken about 6 hours to mill using two passes, each pass requiring a finer tool bit. A composite model was made up from the different sections.

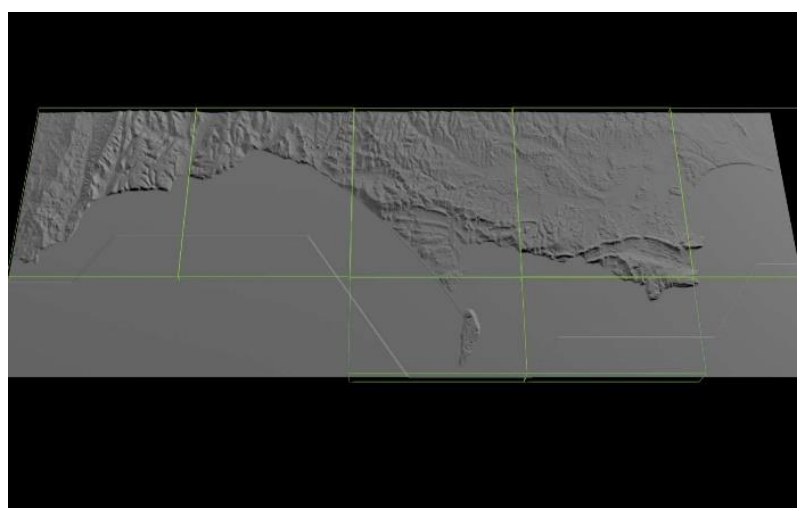

Figure 2: 3D CGI of Jurassic Coast showing sections to be milled.

The rotating tools are of different sizes and shapes and have degrees of freedom to carve material from a block of metal, wood or plastic until the final form is reached. These materials are timber, manmade board and block materials such as PU modelling boards, GRP and Carbon Fibres, MDF, wooden and plastic composites, styrene, acrylic, PVC, PVC foam sheets and other machinable plastics, tooling boards, curable resins, Styrofoam, high density foam boards and blocks and many 
other materials. We chose 540 Necuron because it is dense and captures detail well when milled. Vertical scale exaggeration was necessary when modelling the coastal terrain. A $20 \%$ exaggeration was used to create the visualization required for a $3 \mathrm{D}$ relief map.

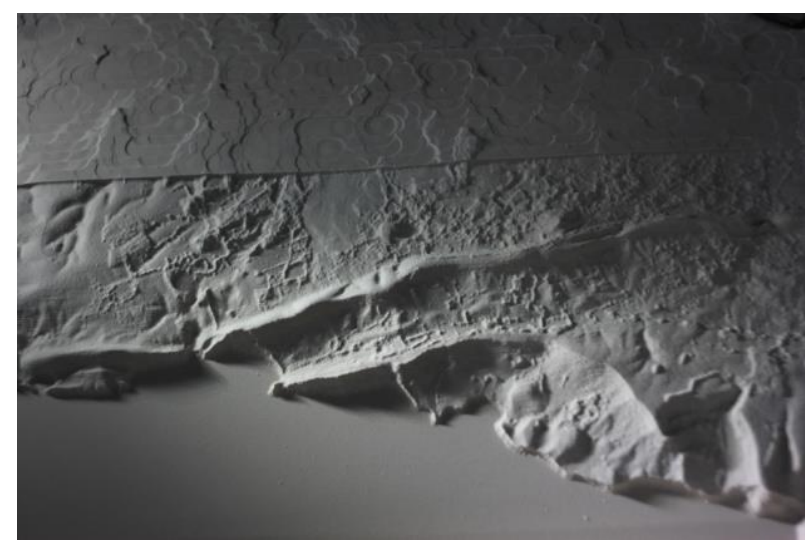

Figure 3: Milled section showing resolution of detail.

An MDF base was built for the five milled map sections and secured to the MDF base. Adjustable bolts enabled the different sections to be orientated on a horizontal plane. Large Neoprene washers support the Necuron sections on the base. The map was then sprayed with a black undercoat in preparation for the transfer of satellite imagery.

A high-resolution photomosaic of satellite imagery of the Devon and Dorset coast was supplied by Andy Ford of Bournemouth University. The data from this $300 \mathrm{~mm}$ print was then painted onto the relief map.

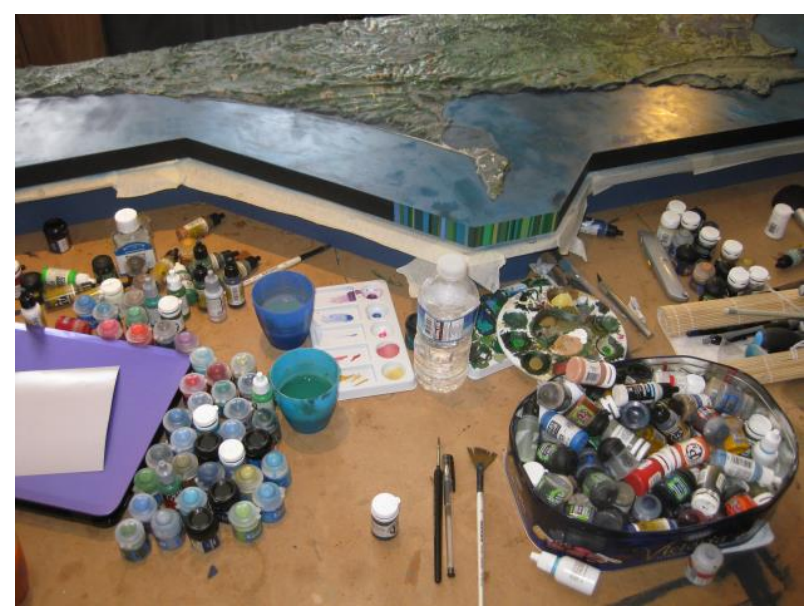

Figure 4: Painting 3D relief map.

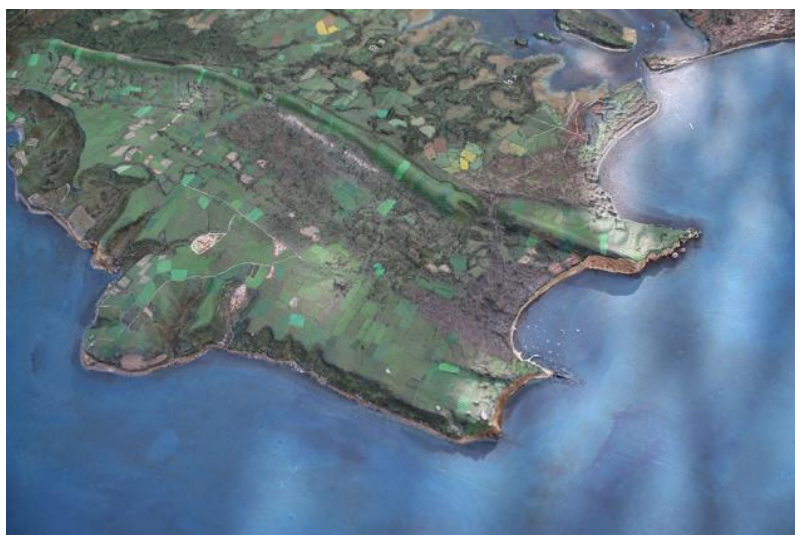

Figure 5: Swanage Bay and Handfast Point, Jurassic Coast.

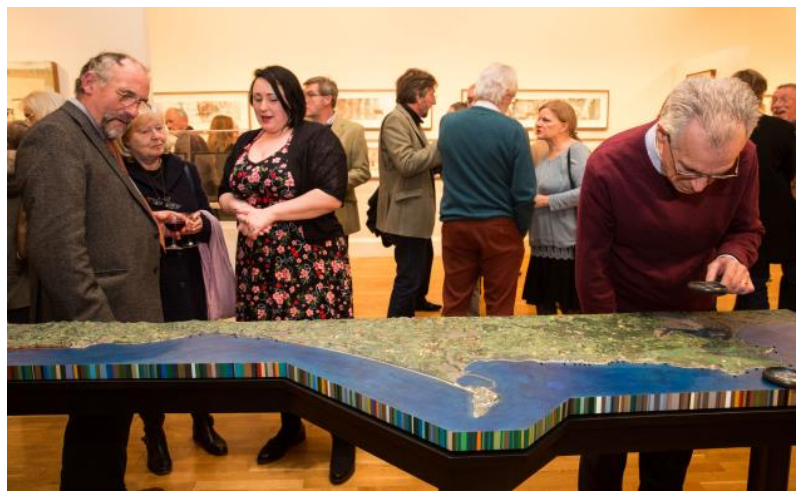

Figure 6: 3D relief map on display.

\section{REFERENCES}

Brunsden, D. and Goudie, A. (1999) Classic Landforms of the West Dorset Coast. The Geographical Association Press.

Davies, G. (1935) The Dorset Coast, A \& C Black.

Winchester, S. (2001) The Map that Changed the World, Viking.

Payne, C. (2013) The Art of Jeremy Gardiner: Unfolding Landscape, Lund Humphries.

Fortey, R. (2002) Fossils: the Key to the Past, Natural History Museum. 